\title{
Child Language Development, Function and Society from a Functional Perspective
}

\author{
Shuguang Zhang \\ School of Foreign Languages, Chifeng University, Chifeng, Inner Mongolia, China \\ 05012311@163.com
}

Keywords: Child language development; Function; Society; Halliday

\begin{abstract}
It is well known that almost every normal child can acquire his mother tongue in a few years after he was born. Language development admittedly is remarkable phenomenon and also a basically universal human achievement. The aspect of child language acquisition attracts great interest from many linguists and researchers and produces many distinct theoretical standpoints. If we can be aware of how and when children get a command of their native language, it may contribute to adults' second language learning and shed some light on our understanding of the nature of language and also the nature of human mind. In this article, it take a look at child language development from Halliday's perspective and endeavor to make clear the relationship between child language development and language function as well as the relationship between child language development and society.
\end{abstract}

\section{The Interpretation of Halliday's Language Theory}

Child Language Development and Language Function. Halliday believes that language is as it is because of the functions it serves. "It is the demands posed by the service of these functions which have molded the shape of language and fixed the course of its evolution" [1]. Halliday [1,2] views Language development in children as the master of linguistic functions, and learning a language is learning how to mean. That is, He maintains that learning language is learning the uses of language and the meaning potential associated with them; the structures, the words and the sounds are the realization of this meaning potential. When a child starts to learn his mother tongue, actually he is touching upon new behavioral modes and thinking ways of human being. During the process of mastering small pieces of basic functions of language little by little, he makes steady, continual and gradual progress and establishes the meaning potential to determine how he can deal with language. In a word, language acquisition should be seen as the mastery of linguistic functions. Learning to speak is learning to mean.

The aim of manipulating language is for communication. Language is achieved through realizing its functions. Halliday [3] suggests a functional interpretation of the child's early language development and summarizes that children come to command seven functions during the process of language development. 1. In its instrumental function, language is used to meet his material needs and get goods and services; this is the 'I want' function. 2. In the regulatory function, language is manipulated to control others' behavior; this is the 'do as I tell you' function. 3. The interactional function is that of getting along with others, which means how to talk with others, the 'me and you' function. 4. In the personal function, the expression of his feelings and of identity is made largely through linguistic interaction; maybe the 'here I come' function. 5. The heuristic function is the use of language to learn, to explore the reality and to know about his own surroundings; the function of 'tell me why'. 6. The imaginative function is that of 'let's pretend', whereby the reality and surroundings are created and the exploration is the child's own mind as well as the language itself. 7. The informative function is the 'I've got something to tell you' function, that of the communication of content, in which information is provided for others.

Halliday [4] points out that the adult's language has to serve more functions and their functions have been reduced to three highly coded and abstract functions, which, called macro-function, consist of ideational, interpersonal and textual functions. 
Child Language Development and Society. Language is the product of social activities. Halliday holds that language in a social perspective interpreted through the concept of meaning potential [4]. If we consider language as social behavior, it means that we are viewing it as a form of behaviour potential. The potential of language is a meaning potential. This meaning potential is the linguistic realization of the behaviour potential [4].

Child language development is a process of socialization of the child. "Language is the main channel through which patterns of living are transmitted the child, through which he learns to act as a member of a society-- in and through the various social groups...to adopt its culture, its modes of thought and action, its beliefs and its values" [5]. This happens indirectly through the accelerated experience of numerous small events, in which his behavior is guided and controlled and he develops personal relationships of all kinds.

The social functions which language is serving in the life of the child thus determine both the available options and the structural realizations of those options. This can be seen clearly in the language of young children once we take language acquisition as the acquisition of the social functions of language and of a meaning potential associated with them.

Halliday continues to state "in order to give an account of language that satisfies the needs of a social theory, we have to be able to accommodate the degree and kind of identification that is appropriate in that context "[4]. We must come out of language and observe its use with the help of sociology theory in order to lucubrate. For language is an essential factor of culture transmission and social variation [6].

We can show something of how our language is related to the situation if we can specify what aspects of the context of situation rule each of the semantic options. The situation consists of the social action, the role of structure and the symbolic organization. When a child learns language, he is also learning other things at the same time through language to build up a reflection of the reality and surroundings that is around him and inside him. In this social process, the explanation of reality is inseparable from the explanation of the semantic system in which the reality is transferred. In this sense, language is a shared meaning potential, at once both a part of experience and an interpersonal interpretation of experience.

Origins of Those Fundamental Theories. Halliday's theory about child language development lies in specifying the functions which language has in society and establishing what reflection these functions find in the structure of the language itself. His theory of language functions derives mainly from two prominent figures: Malinowski and Firth.

Halliday adopts Malinowski in several ways. Firstly, Malinowski [7], an anthropologist, believes that language system comes from functions of child language. Halliday further develops it into the notion that child language development is actually the gradual command of language functions. Secondly, Malinowski thinks language is far from self-contained and entirely dependent on the society to which it belongs. The meaning of an utterance comes from its relation to the situational context where it occurs. Utterances and situation are tied up inextricably with each other and the context of situation is indispensable for the awareness of the words. Based on this, Halliday researches into the relation between language development and society, and interprets language from sociological perspective. Thirdly, Malinowski defines 'meaning' as 'not from a passive contemplation of the word, but from an analysis of its functions, with reference to the given culture'. Halliday takes over the definition of meaning as function in context, of course initially through the mediation of Firth. Lastly, Malinowski identifies three major functions of language: the pragmatic function, the magical function and the narrative function. Halliday accepts his features of language as multi-functional. His interpersonal, ideational and textual functions incorporate some of the facts with Malinowski functions.

Firth [8], influenced by Malinowski, considers language as not only a set of signs and signals but also social process as well as a way of life style. He extends Malinowski's notion that meaning is the function in the social context of certain linguistic item, favorably to the description of all linguistic units. The influence of Firth on Halliday exists in the endeavor to make the linguistic components to go with the sociolinguistic insights of Malinowski. Firth tries to make a match 
between language studies and social studies and observes language from social angle [6], which is an important item taken over and developed by Halliday. Firth carries out sociological research into language from the aspect of meaning which then becomes a major part of Halliday's theory of functional grammar.

Halliday, as the representative of London School, inherits the fundamental theory of London School led by Firth, absorbs some viewpoints from other schools, and ultimately builds up and develops a sociologically and semantically oriented approach to linguistics. Here, we only emphasizes its functional part, which aims to reveal that language is a means of social interaction, based on the assumption that language system and the forms that make it up are inescapably determined by the uses or functions which they serve [5].

\section{Opposite Standpoints from Chomsky}

Quite different from Halliday's theory of language acquisition, Chomsky thinks that the knowledge of language is all in a child's mind. The child does not have to be taught. Language develops in a child in just the same way that other biological functions develop everything. Chomsky [8,9] also makes a clear distinction between competence and performance and holds that linguistic competence is unique to human beings because all languages share some universal features, which is the fundamental concepts of his universal Grammar. while, Halliday does not favor the distinction between linguistic competence and performance. "There is really no need to introduce the artificial concept of 'competence', or 'what the speaker knows', which merely adds an extra level of psychological interpretation to what can be explained more simply in direct sociolinguistic or functional terms." [2]

\section{My Understandings and Comments}

Language appears in the life of the individual through an unceasing exchange of meanings with significant others. A child creates, first his child tongue, then his mother tongue, in communication and interaction with people of that little circle that constitute his meaning group. In this sense, language is undoubtedly a product of the social process. Language function does influence the development of child language and plays an important role. It is his everyday-needs that pushes a child to gradually alter his baby talk, until finally his language form equals that of the adult.

language acquisition is not just the mastery of Grammatically correct sentences, but closely bound up with the children's cognitive and social development. We can notice without much difficulty the fact that children don't stick to their self-invented patterns of language very long. It seems that they change and develop their languages slightly each and every day. Every person they interact with influences their language development and speaking way. And we believe the drive to improve child language comes from his everyday needs. Children are little sociable animals who have two basic needs: food and interaction with other people. So a child will put every effort in learning how to ask for food and services. Gradually the child becomes a carrier of both word and concept and a social creature.

However, Halliday's theory that the child learns language in order to help him to manipulate the world cannot explain why he does not stop learning after obtaining what he wants, nor why we find parallel structural developments in different children. These may be puzzles that Halliday cannot solve and also the reason for us to touch upon the theories beyond him.

Though every coin has two sides, it belongs to the same coin. Hence no two things could ever be absolutely the same or quite different. Different as they are, Halliday and Chomsky are both supposed to belong to the same enterprise called science of language and still have something in common. Halliday $[1,10]$ and Chomsky $[11,12,9,13]$ at least share the fundamental concept that human beings are biologically endowed with the ability to learn language, and that this is a uniquely human attribute. Both of them aim at explaining the nature of the linguistic system and believe that studying how language is learnt by a child can throw a great deal of light on the nature of language 
itself. Only in their particular applications of this common program, can they get quite different results.

\section{Conclusion}

The argument about how language development is achieved has lasted a long time and will continue in future. Even the well-accepted theory from Halliday cannot provide us more satisfactory and convincing answers. Thus, the study about child language development is still the topic that the future researchers exert their efforts for.

\section{References}

[1] Halliday, M. A. K: Language as social semiotic: the social interpretation of Language and meaning (Edward Arnold, England 1978), p.22.

[2] Halliday, M. A. K: Learning how to mean: Exploration in the development of language (Edward Arnold, England 1975), p.32.

[3] Halliday, M. A. K: Explorations in the Functions of Language (Edward Arnold, England 1973).

[4] Kress, G. Ed: Halliday: System and Function in Language (Oxford University Press, England 1976), p.51-54.

[5] LiuRunqing. Ed: Theories and schools of linguistics (Nanjing Normal University, China 2006), p.246.

[6] 刘润清: 西方语言学流派 (北京外语教学与研究出版社, 中国 2007). (In Chinese)

[7] Malinowski. B: The problem of meaning in primitive languages. Supplement to C. K. Ogden and I. A. Richards, the meaning of meaning (Kegan Paul, England 1923).

[8] Firth, J. R: Papers in linguistics 1934-1951 (Oxford University Press, England 1957).

[9] Chomsky, N: Rules and representations (Columbia University Press, America 1980)

[10]Chomsky, N: Knowledge of language: its nature, origin and use (Praeger, America 1985).

[11]Halliday, M. A. K. and Matthiessen, C.M.I.M: Construing experience through meaning (Continuum, England and America 1999).

[12]Chomsky, N: Language and mind (Harper and Row, America 1966).

[13]Chomsky, N: Reflection on language (Pantheon, America 1975).

[14] Chomsky, N: New horizons in the study of language and mind (Cambridge University Press, England 2000). 